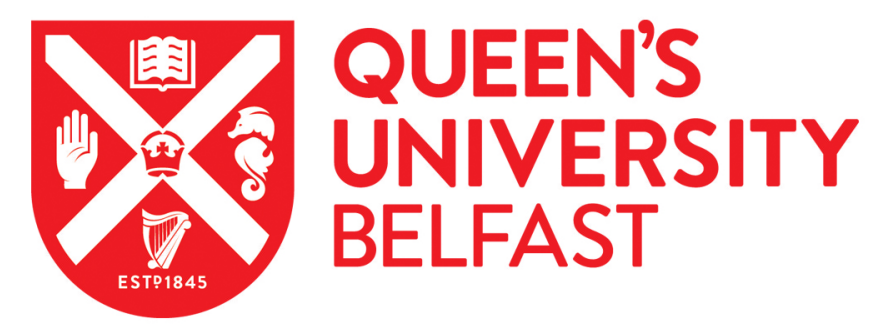

\title{
Stress and Strain Distributions During Compressive Deformation of Titanium Alloy Affected by Microstructure
}

Zhao, Q., Wu, G., \& Sha, W. (2013). Stress and Strain Distributions During Compressive Deformation of Titanium Alloy Affected by Microstructure. JOM, 65(1), 86-92. https://doi.org/10.1007/s11837-012-0518-7

Published in:

JOM

Document Version:

Peer reviewed version

Queen's University Belfast - Research Portal:

Link to publication record in Queen's University Belfast Research Portal

\section{General rights}

Copyright for the publications made accessible via the Queen's University Belfast Research Portal is retained by the author(s) and / or other copyright owners and it is a condition of accessing these publications that users recognise and abide by the legal requirements associated with these rights.

Take down policy

The Research Portal is Queen's institutional repository that provides access to Queen's research output. Every effort has been made to ensure that content in the Research Portal does not infringe any person's rights, or applicable UK laws. If you discover content in the Research Portal that you believe breaches copyright or violates any law, please contact openaccess@qub.ac.uk. 
Research Summary

Stress and strain distributions during compressive deformation of titanium alloy affected by microstructure

Qite Zhao, Guoqing $\mathrm{Wu}^{*}$

School of Materials Science and Engineering, Beihang University, 37 Xueyuan Road, Haidian District, Beijing 100191, China

Wei Sha

School of Planning, Architecture and Civil Engineering, Queen's University Belfast, Belfast BT7 1NN, UK

*Corresponding author.

Telephone and fax: +86 10 82313240; E-mail: guoqingwu@buaa.edu.cn

Abstract

In the research of the microstructural influence on dynamic compression, an assumption that the $\alpha$ and the $\beta$ phases in titanium alloys were linearly strengthened was proposed and a two-dimensional model using ANSYS focusing on the role of micro-geometrical structure was developed. By comparing the stress and strain distributions of different microstructures, the roles of cracks and phase boundaries in titanium compression were studied. 
Keywords: titanium alloys; simulation; plastic deformation; microstructure; dynamic phenomena

\section{Introduction}

The microstructure and composition of a material determine its properties. In titanium alloys, there is a close relationship between microstructure and properties [1]. Previous research by the authors found quantifiable relationship between the static and the dynamic mechanical properties and its microstructural parameters such as $\alpha$ plate length, width and length/width ratio, in a Ti-3Al-4.5V-5Mo alloy [2,3]. For examples, the $\alpha$ plate length/width ratio is inversely proportional to the width of the shear band during compression, the alloy tensile strength is proportional to the length/width ratio, and the crack formation energy is proportional to the length/width ratio. However, the previous research by the authors on the microstructural parameters was confined to the annealing processing adjustment range, for the length/width ratio within 6.2-7.5. During annealing, the $\alpha$ plate length and width change independently, which increases the difficulty of experimental research. Therefore, using numerical simulation to study the effect of microstructural changes in a wider domain on the mechanical properties can be important in identifying the titanium alloy microstructure for optimal dynamic processing properties. At present, the research on the microstructure of titanium alloys is concentrated on the influence of thermomechanical deformation processing parameters on the material microstructure $[4,5,6]$ and the effect of heat treatment on microstructure and mechanical properties [1]. Simulation work on the other hand is concentrated on the evolution of microstructures [1,7]. In the field of composites, there have been many 
experimental and modelling studies on the effect of strengthening phase microstructural parameters on the mechanical properties of the composite materials. However, such computer simulation on the effect of microstructural parameters on the mechanical properties of titanium alloys has not been well conducted.

In order to analyse the effect of titanium alloy microstructural characteristics on dynamic compression deformation, the present work has established a numerical model for dual phase titanium alloys. The modelling uses ANSYS software package and it includes micro-geometrical morphology parameters. The model can be used to study and compare the stress and strain distribution characteristics under different microstructural conditions, and to analyse the quantitative effects of $\alpha$ plate length/width ratio, crack, and phase boundaries on micro stress and strain distributions during compression deformation. Exploring and evaluating the possible effects of microstructure on the mechanical properties of titanium alloys are potentially useful in the material design for cold compression of these alloys.

\section{Theory and calculation}

The study of the effects of $\alpha$ orientation, crack, and phase boundaries is achieved through setting up a multi-cell model and introducing phase boundaries and crack models. 


\subsection{The material model}

In the material model, we assume that the titanium alloy strain hardens linearly. This agrees with experimental testing data within certain deformation ranges. The material data used in modelling are listed in Table 1. The stress-strain curves are shown in Fig. 1.

The elastic modulus is a physical parameter reflecting the strength of the atomic bonding in crystals, and is thus not microstructural sensitive. The factors affecting the elastic modulus of metallic materials are from the composition and solid solution of metallic alloys. In titanium alloys, the $\alpha$ and the $\beta$ phases have different crystal structures. The $\alpha$ phase has a hexagonal close packed (HCP) structure, and the $\beta$ phase has a body centred cubic (BCC) structure. Thus, the $\alpha$ phase has a higher elastic modulus. The $\beta$ phase has much higher yield strength than the $\alpha$ phase. Data for some common titanium alloys are shown in Table 2. Strain hardening is affected by many factors, such as temperature and compression speed. However, the slip resistance of $\mathrm{HCP}$ crystal is larger than $\mathrm{BCC} \beta$ phase, which results in lower hardening of the latter.

As for the elasticity heterogeneity consideration, the following explanation is provided. The $\beta$ phase is of cubic crystal structure, which makes its elasticity heterogeneity far less than the $\alpha$ phase that has the HCP crystal structure and has only one close packed plane, (0001). Therefore, if considering all the situation of elasticity heterogeneity, it may be accomplished in the $\beta$ phase, but for the $\alpha$ phase, it will be too overwhelming, and all the data thus obtained should be calculated statistically to 
obtain a result that is comparable in different aspect ratios. Luckily, we do not need this bureaucratic process because the macro elastic modulus is the same as the abovementioned calculated resultant. This is why the material model usually used in macroscopic scale is used here. However, it is worth mentioning that the approximation suggests that the texture in pure $\alpha$ titanium alloys and pure $\beta$ titanium alloys are the same for the respective $\alpha$ phase and $\beta$ phase. The texture effect was not considered. For materials without sharp textures, this approximation is applicable, but for titanium alloys, this approximation may subject the results to some errors.

As the modelling work in this paper has emphasis on the elastic part instead of the plastic part, to simplify the modelling process, the homogeneous linear hardening material model is used for $\alpha$ and $\beta$ phases. For the same reasons, the crystal plasticity model was not adopted in the calculations here.

\subsection{The multi-cell model}

Within one microstructure type, the $\alpha$ plate length, width and aspect ratio change systematically with annealing temperature and time. Microstructural observation shows that in a larger scale, the orientation of the $\alpha$ plates is random, but the adjacent few $\alpha$ plates have a same direction and form a plate group. Simplifying this physical morphology, the following multi-cell model is set up (Fig. 2). In the matrix of the $\beta$ phase, we use ovals of different length-to-width ratio to represent $\alpha$ plates. When considering the effect of crack and the weak phase boundary regions, the geometrical model will be modified slightly from this model. Plane2 six-node triangle mesh [8] was used during simulation. The size of the mesh is half of the minimum distance 
between plates. By changing mesh size for different aspect ratio, the computation time can be reduced. The calculation was over 60 steps, with results saved every five steps.

In the following two sections, stress and strain distribution simulation results are shown based on multi-cell models, for different length-to-width aspect ratios. Furthering and improving the multi-cell model, stress and strain distributions after introducing crack and phase boundary weak region have been simulated. The effects of the aspect ratio, crack and phase boundary on the stress and strain distributions at a micro level during compression deformation are discussed.

3. The influence of aspect ratio on stress and strain distributions at phase boundaries

This section describes simulation results of the distributions of effective stress and effective plastic strain as functions of the aspect ratio during compression conditions, based on multi-cell models with different $\alpha$ plate aspect ratios, with fixed $\alpha$ plate width. The compression degree is $20 \%$. The simulated effective strain distribution is shown in Fig. 3. It can be seen that, under the same deformation degree, with increasing aspect ratio, Von Mises strain moves to the middle of the $\alpha$ plates. Such transfer of the plastic strain will reduce the strain gradient inside the $\alpha$ plates, and help the $\alpha$ plates rotate. Because this model does not consider friction at the top and the bottom of the cell, the whole specimen will be under single direction stress, if the microstructure were uniform. So, the magnitude of the shear stress can be used as a measure of coordinated material deformation. As can be seen from Fig. 4, with increasing aspect ratio, the region for maximum shear stress shrinks and eventually 
disappears. The variation of the shear stress between $\alpha$ plates is shown in Fig. 5. We can see that, with increasing aspect ratio, the shear stress between the plates decreases continuously, i.e., the $\beta$ phase acts as a strengthening phase to better effects. This could be the reason for higher yield strength of titanium alloys having large aspect ratios [9], i.e., yield strength decreasing from the weave basket structure to Widmanstätten structure to equiaxed structure.

Because phase boundaries play an important role in material deformation, in order to more visually clearly observe this effect and their effects on crack propagation, we now add a layer of new material at the interface between the $\alpha$ and the $\beta$ phases in simulation. Its strength is assumed one third of the $\alpha$ phase strength. This, and other parameters used for the boundary layer, are included in Table 1.

The atom arrangements in boundaries tend to be more irregular, corresponding to a lower elastic modulus. This parameter is more important to modelling in this paper, because elastic stored energy is the main consideration. Because the elastic modulus of the interface is assumed one third of the $\alpha$ phase, its yield strength is assumed one third as well, to make them yield at the same strain. However, the boundary should have a higher strain-hardening rate, due to high dislocation density and dislocation pile-up. There is no literature reference for the actual values used, and they are estimates or approximations for modelling here.

This boundary thickness is set at one tenth of the $\alpha$ plate thickness. The cell, boundary conditions and the mesh generation are the same as for the multi-cell model. Fig. 6 shows this geometrical model, which consists of three different material 
parameters $(\alpha, \beta$, and the interface layer). $\mathrm{AD}$ and $\mathrm{AB}$ sides are symmetrical axes, $\mathrm{BC}$ is the free surface, and the load in displacement mode is applied on the DC side. The deformation degree is $5 \%$. Fig. 7 shows the simulated distribution of the effective strain corresponding to structures having aspect ratio between 2 and 6 .

From this figure, we can see that the phase boundaries coordinate the deformation, but this coordination effect reduces with increasing aspect ratios. When the aspect ratio is 4, though the inter-phase regions are the weak areas, the effective strain values there are quite small, similar to the matrix. The deformation degree of the phase boundaries is different for different $\alpha$ plate aspect ratios, which can influence significantly the material deformation behaviour. Because the effective strain at boundaries is not large in the high aspect ratio material, the crack tends to propagate through the $\alpha$ plates. With increasing $\alpha$ plate length for a fixed width, the probability of the crack going round the $\alpha$ plate decreases, which reduces the path distance of the crack propagation and thus the energy required for the crack propagation. This is detrimental to the dynamic compression property of the material. This has been verified experimentally within the aspect ratio range of 6-7.5.

We may imagine that many "micro springs" form in the material. Once the material behaviour deviates from linear hardening, the release of this energy will soften the material. The coordination effect of the phase boundaries during deformation decreases with increasing aspect ratio. This probably causes the crack propagation mode to change from inter-crystalline, i.e. boundary, propagation to trans-crystalline propagation. The net effect is detrimental to the dynamic deformation property of titanium alloys. On the other hand, with increasing aspect ratio, the strengthening 
effect of the $\beta$ phase is better used, and the deformation coordination between the two phases is improved. Under the same strain conditions, the maximum effective stress and the effective plastic strain decrease, which help improve the static mechanical properties of the material. This has been verified experimentally.

4. Crack induced phase boundary stress relieve in dual phase titanium alloys

During the dynamic compression of titanium alloys, usually, microcracks form before the fracture. In areas around the cracks, locally, the material usually is under tensile stress and shear stress. In this section, we will compare the effective stress (Fig. 8) and strain (Fig. 9) contours of specimens having an aspect ratio of 7 under unidirectional compression. The deformation degree is $3 \%$. The results are analysed below.

From the simulation results, the introduction of the crack has a dominating effect on the stress and strain distributions. It in fact completely changes the original stress and strain distributions. The maximum effective strain appears in front of the crack, and is 0.31 , about ten times of the average effective strain. In addition, a characteristic strain field is formed at the crack front. The presence of the crack relieves the effective stress in the $\beta$ phase greatly. Its extreme value is also at the crack front, at $1652 \mathrm{MPa}$, far greater than the average level in the specimen. With increasing aspect ratio, the "equivalent springs" can store a greater amount of energy, but the crack propagation can effectively release this part of the energy, by using it as the energy required for the crack propagation. Thus, for titanium alloys with large aspect ratios, the crack propagation is relatively easy. This has been verified experimentally. 


\section{Conclusions}

In order to analyse the influence of titanium alloy microstructural characteristics on its dynamic compression deformation, a multi-cell numerical model of dual-phase titanium alloys has been developed using the ANSYS software, for different geometrical morphological parameters at a micro level. The stress and strain distribution characteristics are compared for different microstructural conditions. The effects of cracking and phase boundaries on micro stress and strain distributions during compression deformation are discussed, quantitatively. It was found that the introduction of a crack releases the non-uniform stored energy.

\section{References}

[1] Sha W., Malinov S. Titanium alloys: modelling of microstructure, properties and applications, Woodhead Publishing, Cambridge, 2009.

[2] Song H., Wu G.Q., Zhang Z.G., Huang Z., Ruan Z.J. Effects of microstructural variations on dynamic compressive deformation behavior of Ti-3Al-5Mo-5V alloy. Materials Letters, 2006, 60(28): 3385-3389.

[3] Wu G.Q., Sha W. Modeling the cold deformation of titanium alloys. JOM, 2009, 61(5): 51-55.

[4] Charpentier M., Hazotte A., Daloz D. Lamellar transformation in near- $\gamma$ TiAl alloys-quantitative analysis of kinetics and microstructure. Materials Science and Engineering A, 2008, 491(1-2): 321-330. 
[5] Chen H., Cao C.X, Guo L., Lin H. Hot deformation mechanism and microstructure evolution of TC11 titanium alloy in $\beta$ field. Transactions of Nonferrous Metals Society of China, 2008, 18(5): 1021-1027.

[6] Dey S.R., Suwas S., Fundenberger J.-J., Zou J.X., Grosdidier T., Ray R.K. Evolution of hot rolling texture in $\beta$ (B2)-phase of a two-phase $(\mathrm{O}+\mathrm{B} 2)$ titanium-aluminide alloy. Materials Science and Engineering A, 2008, 483484: $551-554$

[7] Mebed A.M., Koyama T., Miyazaki T. Spinodal decomposition existence of the $\beta$ Ti-Cr binary alloy: computer simulation of the real alloy system and experimental investigations. Computational Materials Science, 1999, 14(1-4): $318-322$.

[8] ANSYS Coupled-field Analysis Guide, ANSYS Release 10.0, ANSYS, Inc. and ANSYS Europe, Ltd., 2005.

[9] Li X.W., Lu M.X., Sha A.X., Zhang L. The tensile deformation behavior of Ti-3Al-4.5V-5Mo titanium alloy. Materials Science and Engineering A, 2008, 490(1-2): 193-197. 
Table 1 . The mechanical properties of $\alpha$ and $\beta$ phases in titanium alloys

\begin{tabular}{lllll}
\hline Phase & \multicolumn{1}{l}{ Elastic modulus $(\mathrm{MPa})$} & Yield strength $(\mathrm{MPa})$ & Poisson's ratio & Strain hardening rate $(\mathrm{MPa} / \%)$ \\
\hline$\alpha$ & 120,000 & 600 & 0.3 & 10,000 \\
$\beta$ & 80,000 & 900 & 0.3 & 8,000 \\
Interface & 40,000 & 200 & 0.3 & 20,000 \\
\hline
\end{tabular}

Table 2. Yield strength of some $\alpha$ and $\beta$ type titanium alloys

\begin{tabular}{lllll}
\hline & $\alpha$ alloys & \multicolumn{1}{l}{$\beta$ alloys } \\
\hline Composition & Ti-5Al-2.5Sn & Ti-2.5Cu & Ti-5Mo-5V-8Cr-3Al & Ti-15V-3Al-3Cr-3Sn \\
Yield strength in annealed state (MPa) & 680 & 400 & $885-980$ & 1060 \\
\hline
\end{tabular}




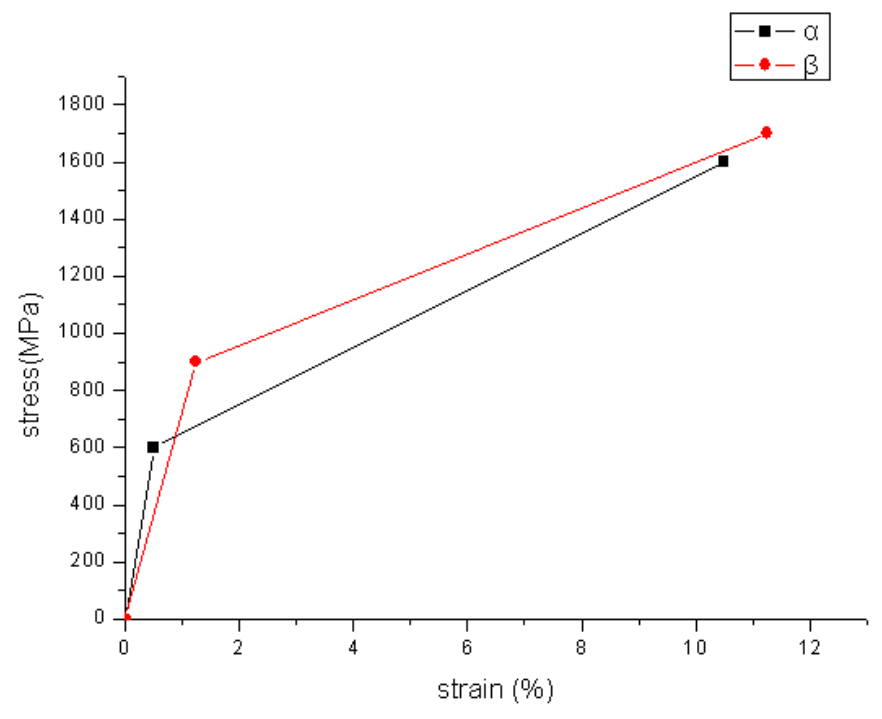

Fig. 1. Linear strain hardening constitutive model for $\alpha$ and $\beta$ phases.

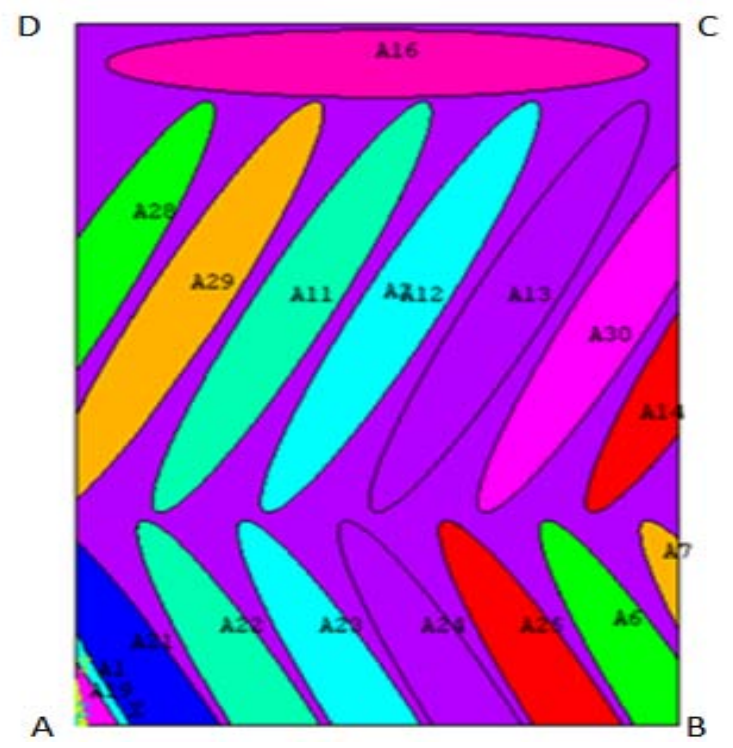

(a)

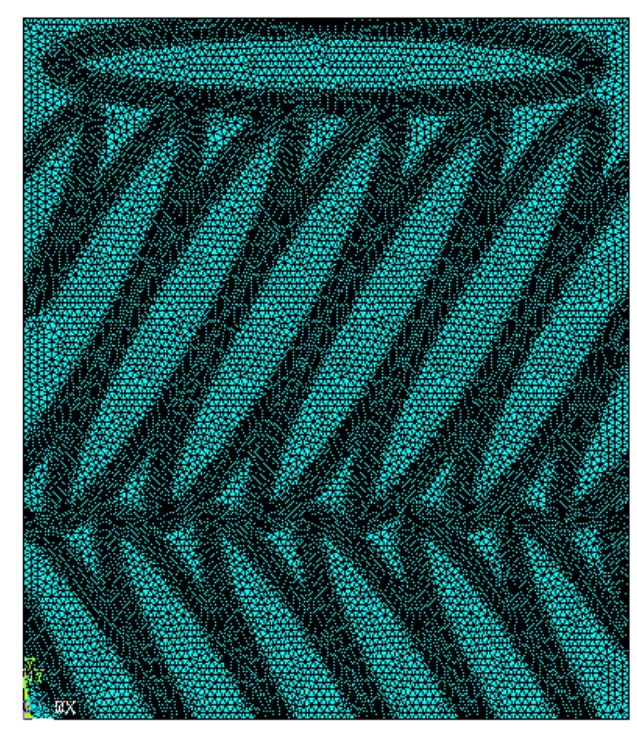

(b)

Fig. 2. Multi-cell plate microstructure of titanium alloys. (a) Geometrical model; (b) mesh. The boundary conditions are $\mathrm{AB}$ no movement in the vertical direction, $\mathrm{AB}$ and $\mathrm{AD}$ symmetry, $\mathrm{BC}$ free surface, and DC downward displacement loading. 


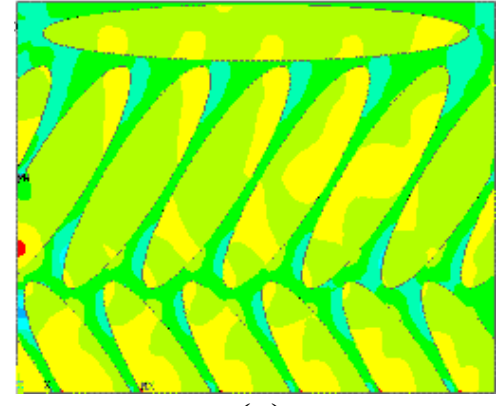

(a)

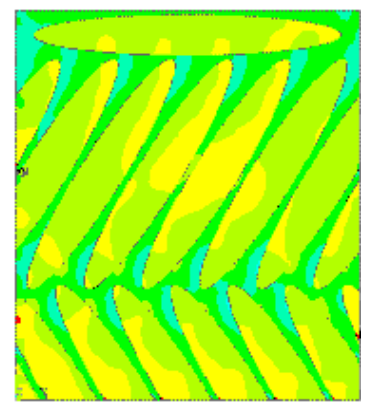

(d)

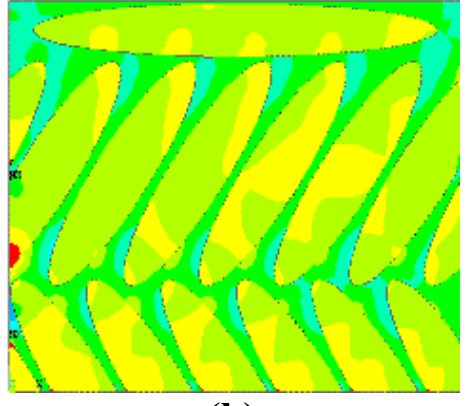

(b)

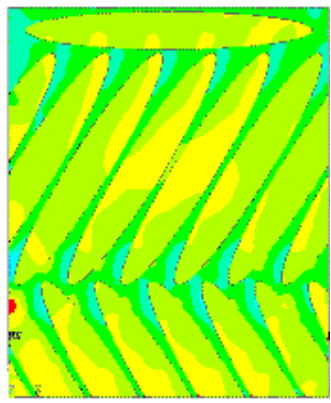

(e)

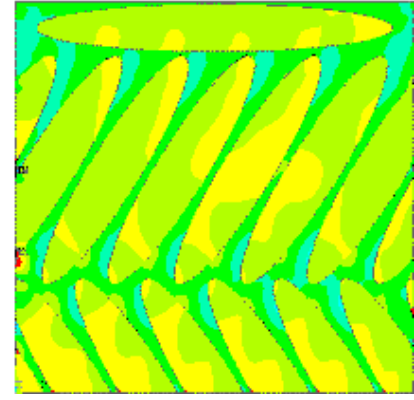

(c)

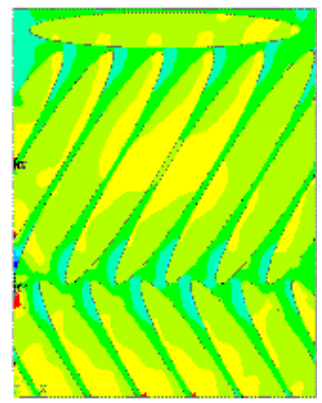

(f)

181

.184

.187

.19

.193

.196

.199

.202

.205

Fig. 3. Von Mises plastic strain contours of the BT16 titanium alloy having different aspect ratios: (a) 4.5; (b) 4.8; (c) 5.5; (d) 6.5; (e) 7; (f) 7.5. 


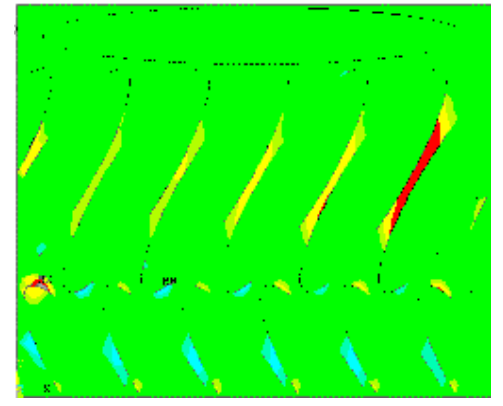

(a)

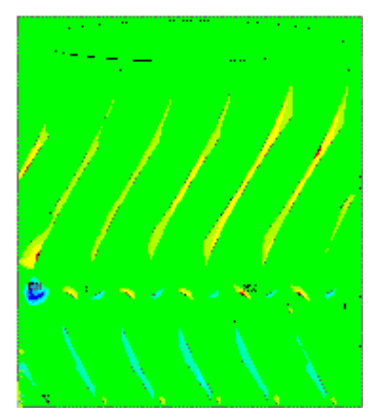

(d)

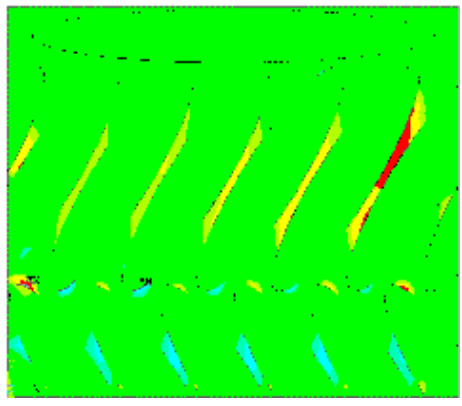

(b)

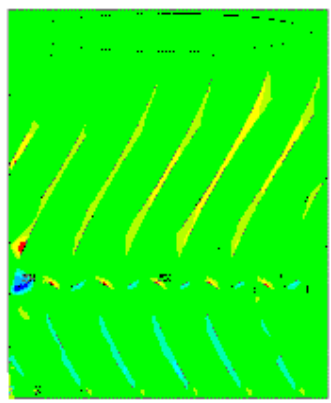

(e)

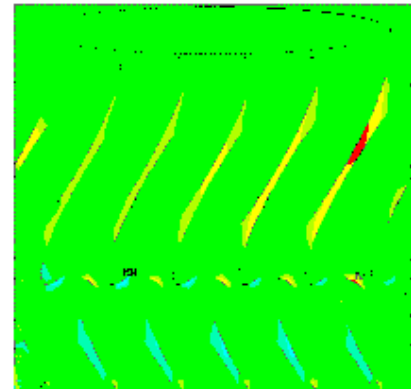

(c)

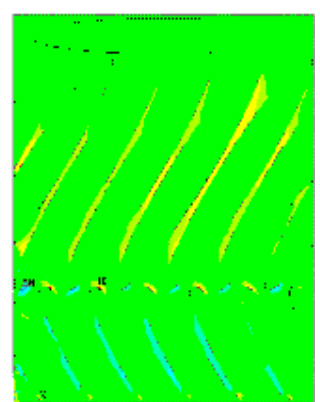

(f)

$\begin{array}{lllllllll}-110 & -95 & -80 & -65 & -50 & 50 & 65 & 80 & 95 \mathrm{MPa}\end{array}$

Fig. 4. Shear stress contours of the BT16 titanium alloy having different aspect ratios: (a) 4.5 ; (b) 4.8 ; (c) 5.5 ; (d) 6.5 ; (e) 7 ; (f) 7.5 .

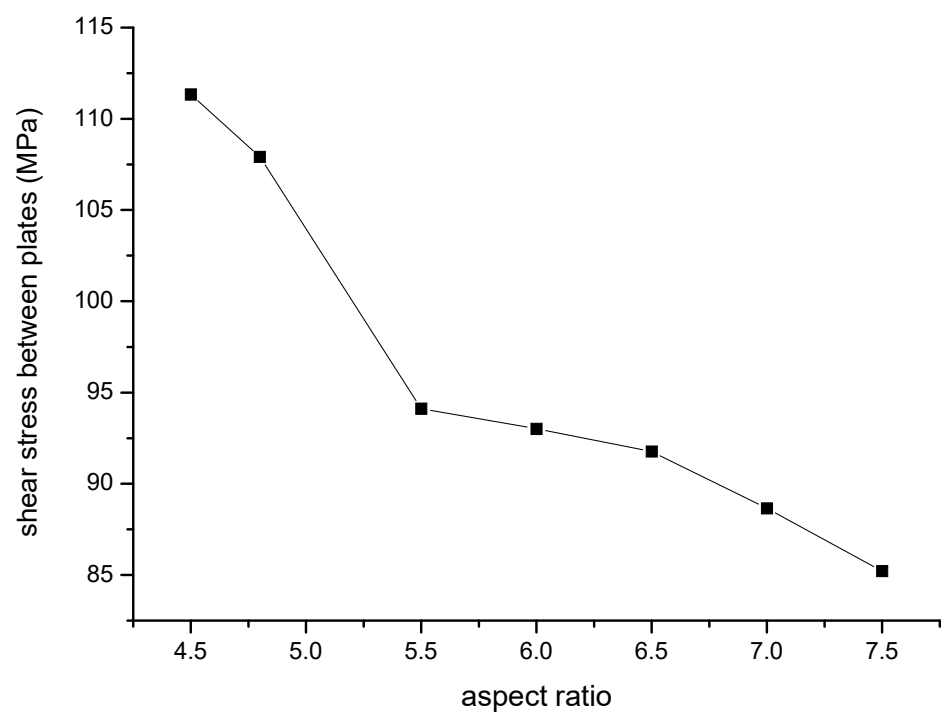

Fig. 5. The relationship between the aspect ratio and the inter-plate shear stress. 


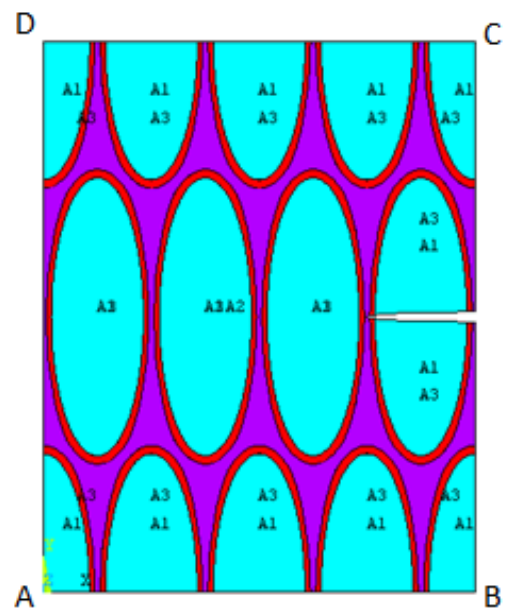

Fig. 6. Multi-cell model containing phase boundaries.
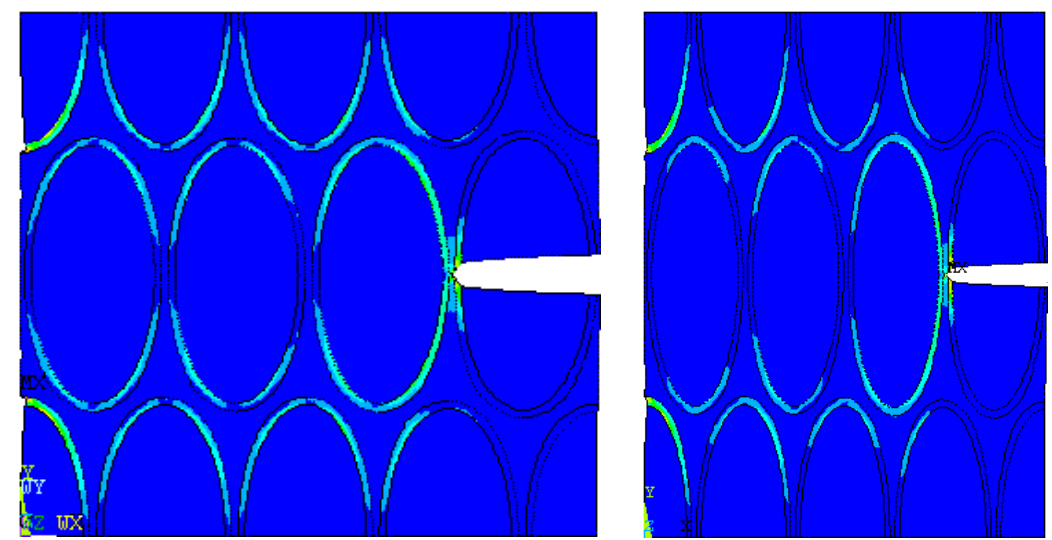

(a)

(b)
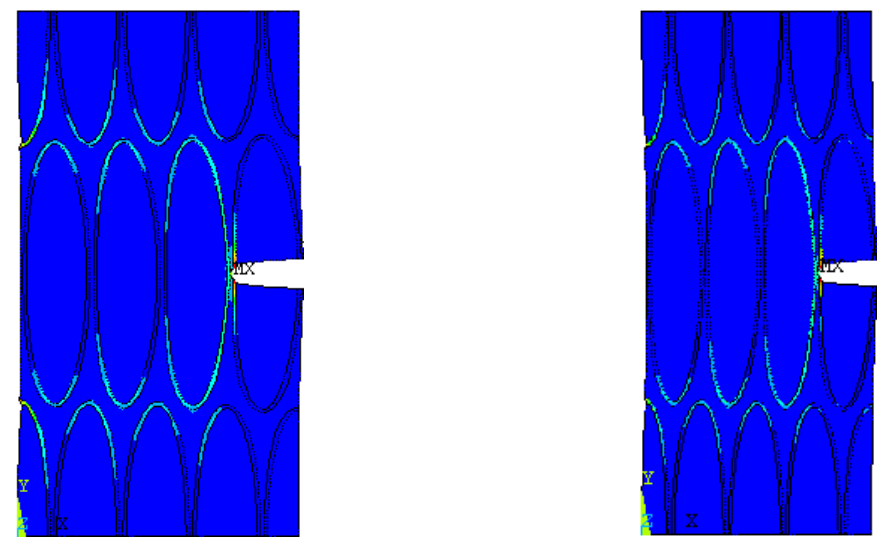

(c)

(d)

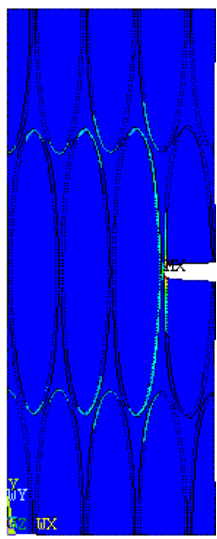

(e)

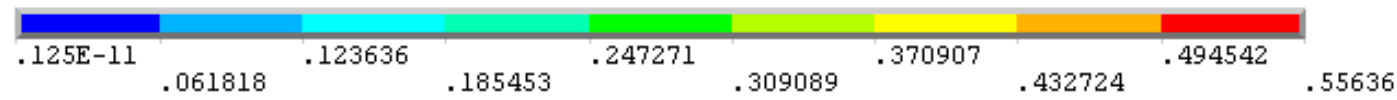

Fig. 7. Coordinated deformation around phase boundaries for different aspect ratios:

(a) 2 ; (b) 3 ; (c) 4 ; (d) 5; (e) 6 . 


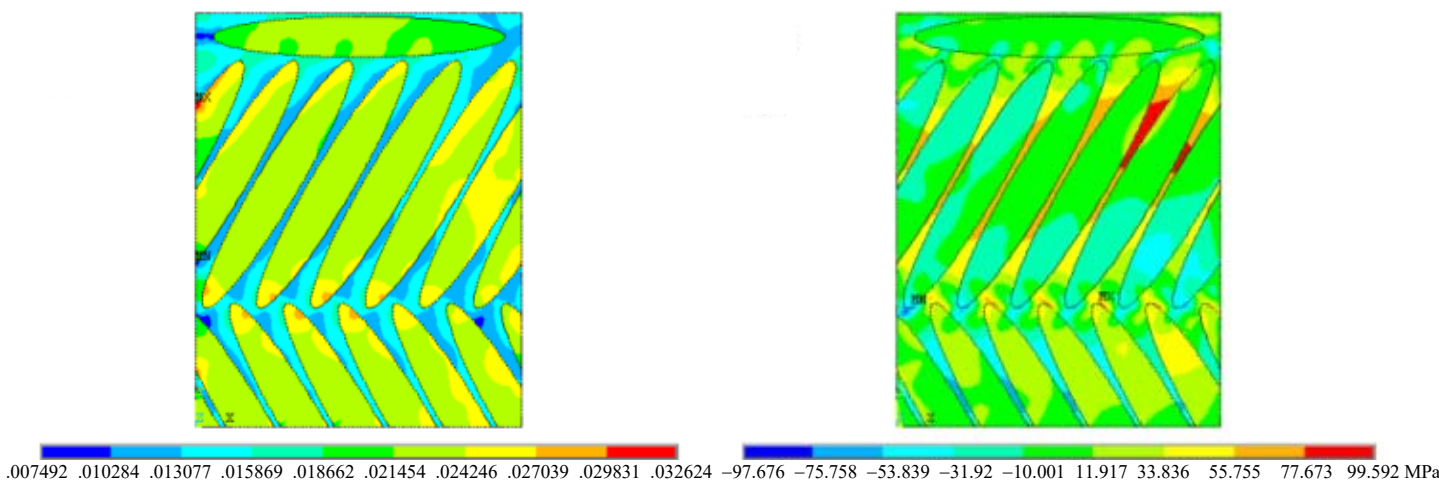

(a)

(b)

Fig. 8. Effective strain (a) and effective stress (b) contour diagrams in the absence of crack. Compression degree 3\%.
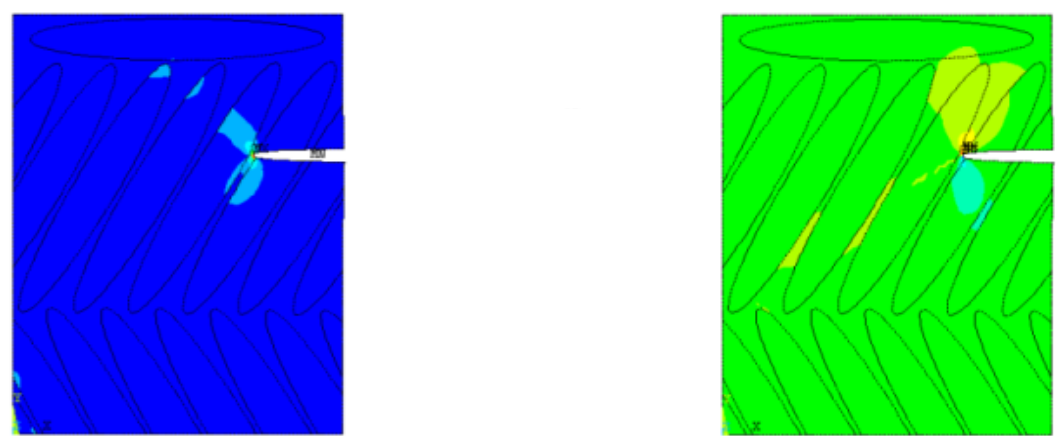

$.000002 .035058 .070116 .105175 .140233 .175291 .210349 .245407 .280466 .315524-100000$

(a)

(b)

Fig. 9. Effective strain (a) and effective stress (b) contour diagrams in the presence of crack. Compression degree 3\%. 